Disponível em

http://www.anpad.org.br/rac

RAC, Rio de Janeiro, v. 19, n. 4, art. 5, pp. 508-524, Jul./Ago. 2015

http://dx.doi.org/10.1590/1982-7849rac20151864

$((c)$ EY-NO

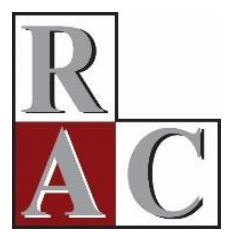

\title{
Previsão de Informações para Avaliar Políticas Públicas: O Caso da Inclusão Financeira
}

\author{
Provisioning Information to Evaluate Public Policies: A Financial Inclusion Case
}

Eduardo Henrique Diniz

Fundação Getúlio Vargas - FGV 


\title{
Resumo
}

Neste artigo, discute-se a importância de se prever a obtenção das informações necessárias para a avaliação de políticas públicas durante a fase de formulação. Entretanto, muitas vezes as políticas vão se redefinindo durante o processo de implementação. Essa característica se manifesta especialmente quando o Estado é o formulador e os implementadores são, em larga escala, agentes independentes, como é o caso da política discutida neste artigo: a inclusão financeira promovida pelo Banco Central do Brasil (BC). Assim como outras políticas do BC, a inclusão financeira foi sendo formulada internamente na instituição e implementada diretamente por agentes do sistema financeiro. Dadas essas características, investigamos o caso à luz de teorias que articulam formulação, implementação e avaliação de políticas públicas. Com base neste estudo concluímos que, apesar da impossibilidade de se fazer uma previsão completa das informações necessárias na fase de formulação, há ganhos para o processo de avaliação se ele for inserido na dinâmica de formulação/implementação das políticas públicas.

Palavras-chave: previsão de informações; avaliação de políticas públicas; inclusão financeira; Banco Central do Brasil.

\begin{abstract}
The aim of this paper is to investigate the importance of providing information necessary for the evaluation of public policies during the formulation phase. These policies often can be reformulated or adapted during the deployment process, making it difficult to identify during the formulation phase what information is needed for evaluation. This difficulty is especially manifested when the state is the formulator and independent agents are deployers, such as the financial inclusion policy discussed in this paper. Like other Central Bank (CB) policies, the financial inclusion project was formulated internally in the $\mathrm{BC}$ and implemented directly by financial system agents. Given these characteristics, we investigate this project under light of theories that articulate formulation, implementation and evaluation of public policies. From this study we conclude that, despite the impossibility of making a full estimate of the required information in the formulation stage, there are gains for the evaluation process if it is inserted into the formulation/implementation dynamics of public policies.
\end{abstract}

Key words: information provisioning; public policy evaluation; financial inclusion; Central Bank of Brazil. 


\section{Introdução}

A preocupação com a avaliação de políticas públicas cresce na mesma proporção que o interesse dos governos pela garantia da aplicação eficiente dos investimentos públicos, bem como pela pressão para aumentar a accountability da gestão pública, com o propósito de reduzir a assimetria de informação entre cidadãos e políticos e entre políticos e burocratas (Ceneviva \& Farah, 2012). Contudo, ainda convivemos com dificuldades frequentes para avaliar as políticas públicas, como a baixa disponibilidade de dados ou o fato de muitas políticas não terem sido desenhadas para serem avaliadas (Ramos \& Schabbach, 2012).

Dados e informações são essenciais para avaliar uma política pública. Qual é a importância de se prever a obtenção desses dados e informações? E quais seriam os limites dessa previsão? Na busca por responder a essas questões de pesquisa, emergiu uma terceira: Pensando em termos das etapas do ciclo da política pública, qual seria o momento para se fazer a referida previsão? Ainda na formulação? Durante a implementação? Ao iniciar-se a avaliação? (Como será apontado no referencial teórico, as etapas - ou fases - do ciclo da política não são tão claramente distinguíveis, e o próprio ciclo não deve ser entendido como sequência linear ou rígida.).

Os dados e informações necessários para realizar a avaliação, em regra geral, não são obtidos automaticamente, sem esforço, problemas ou custos (Behn, 1995). Mais ainda: independentemente do esforço (necessário) ou dos recursos despendidos, a informação perfeita não se verifica na prática. Simon (1957), um dos precursores da área de políticas públicas, relaciona, entre os problemas que limitam a racionalidade dos decisores públicos, precisamente a informação imperfeita. Essa suposição sugere que se conte com informações satisfatórias (o que é possível obter, ou ao menos almejável) e tempestivas (sem as quais o decisor não se satisfaz) (Garcia, 2001), o que dificilmente se alcança sem previsão. Dados e informações para avaliar a política pública são em parte previsíveis desde a fase de formulação da política pública. Neste artigo, discute-se a oportunidade de prevê-los, ao menos em parte, nessa etapa inicial. Contudo, uma política não sai pronta da fase de formulação, pois ela é construída também ao longo de sua implementação (Hill, 2006; Majone \& Wildavsky, 1995; Subirats, Knowepfel, Larrue, \& Varone, 2012). Formulação e implementação são processos fortemente imbricados. Assim, é preciso falar de redefinições e ajustes pós-formulação (ou formulação que continua na implementação). Antecipar processos da avaliação nessas etapas - prevendo dados e informações - supõe imbricar avaliação, formulação e implementação, o que é raramente discutido na literatura. A propósito, Melo (1999) chama atenção para a grande fragmentação temática da literatura sobre políticas públicas no Brasil, havendo particular carência de estudos dedicados aos processos de implementação e avaliação de políticas - quanto mais se o objeto for a interligação desses processos.

Os limites da referida previsão são impostos, entre outras razões, pela citada reformulação da política pública durante a sua implementação e pela necessidade de ampliá-la para além das fronteiras da administração pública (Arretche, 2001; Farah, 2011; Silva \& Melo, 2000), o que torna ainda mais complexos e imprevisíveis os processos de formulação, implementação e avaliação de políticas públicas. A partir da análise da política de inclusão financeira promovida pelo Banco Central do Brasil (BC) no período de 1999 a 2012, este artigo discute os desafios e também os possíveis benefícios de se inserir a previsão de dados para avaliação ainda na dinâmica de formulação/implementação das políticas públicas.

\section{Formulação, Implementação e Avaliação de Políticas Públicas}

Nas questões de pesquisa, bem como no título do artigo, não se utilizou o verbo planejar, e sim prever. A motivação não foi linguística, mas teórica, para evitar um destaque indevido ao planejamento, que não é o foco deste estudo. Do ponto de vista teórico, este artigo vincula-se aos processos de formulação, implementação e avaliação de políticas públicas. 
A conceituação de política pública está longe de ser consensual (Secchi, 2010; Souza, 2006). Para os propósitos deste artigo, refere-se primordialmente a escolhas do governo (fazer ou não fazer) (Dye, 1992). Como se verá, essas escolhas, na prática, configuram-se mais como direcionamentos do que definições rígidas.

$\mathrm{Na}$ abordagem conhecida como ciclo da política pública, esta é vista como um conjunto não rígido de etapas, entre as quais se destacam formulação, implementação e avaliação (Frey, 2000; Souza, 2006). Pressman e Wildavsky (1984, como citados em Majone \& Wildavsky, 1995) perguntam: O que vem antes, a galinha dos objetivos (formulação da política) ou o ovo da implementação? Se o senso comum tende a responder que a formulação antecede a ação (implementação), na prática e para o caso específico de políticas públicas, a resposta não é assim tão simples. A abordagem conhecida como de cima para baixo (top-down) faz uma distinção clara entre as etapas de formulação e implementação. Oferece uma leitura do ciclo da política que sublinha a formulação, quando seriam tomadas as decisões que desenham a política. Quer dizer, haveria uma separação bem definida entre concepção e execução, entre política e administração. O plano, que define a rota e o controle, que detecta e corrige eventuais desvios, recebe grande destaque (Subirats et al., 2012).

Em contraposição a essa abordagem, surgem modelos de implementação conhecidos como de baixo para cima (bottom-up), que têm em comum pressupor que os implantadores agem com grande autonomia. Uma das críticas à abordagem top-down é que ela não seria capaz de incorporar contribuições não previstas na formulação original da política, surgidas dos processos sociais e políticos típicos da fase de implementação. Para Subirats, Knowepfel, Larrue e Varone (2012), os adeptos da perspectiva bottom-up consideram que essas contribuições não previstas demonstram que um mesmo plano "pode suscitar esperanças, reações e estratégias divergentes segundo os interesses dos atores públicos e privados envolvidos no jogo" (p. 189).

Nessa perspectiva, enfatizam-se não mais os controles, mas os incentivos capazes de induzir os agentes implantadores a aderir aos objetivos da política, que, aliás, não sairia pronta da fase de formulação, mas seria construída também na fase de implementação (Hill, 2006). "A implementação é entendida como processo autônomo onde decisões cruciais são tomadas e não só 'implantadas" (Silva $\&$ Melo, 2000, p. 11). Arretche (2001), como outros autores, enfatiza a implementação, mas sem esvaziar a formulação:

um programa [público] é o resultado de uma combinação complexa de decisões de diversos agentes. É claro que nesta cadeia de interações a concepção original, tal como apresentada na formulação é, sem dúvida, muito importante, porque as decisões tomadas durante esta fase já excluíram diversas alternativas possíveis (Arretche, 2001, p. 3).

Lindblom (1959) define política pública como um processo de sucessivas ações em direção ao objetivo desejado. Essa visão caracteriza uma abordagem incremental, que levaria os dirigentes a esperar que suas ações resultassem em passos sucessivos em direção às suas metas. Segundo o autor, um dirigente sábio entende que uma política pública atinge apenas parte do esperado, pois produz necessariamente consequências imprevistas. A perspectiva incremental propicia, de certa forma, maior conciliação entre formulação e implementação.

Visando precisamente a essa conciliação, Majone e Wildavsky (1995) propõem uma terceira via. Para eles, os constituintes essenciais de qualquer política são os objetivos e os recursos. Como os objetivos, caracteristicamente múltiplos, conflitivos e vagos, não têm uma única forma de serem determinados, de igual modo as formas de implantá-los não são únicas. Quanto aos recursos, em razão de nossas limitações cognitivas e da característica dinâmica do ambiente, só conseguimos compreender suas particularidades quando o processo de implementação progride; apenas então podemos incorporar esse novo conhecimento em nossos planos.

Enquanto não se determina exatamente o que é viável, não convém levar adiante políticas de forma unívoca. Tudo o que se pode fazer, ainda segundo Majone e Wildavsky (1995), é conduzir um conjunto de políticas potenciais. Planos, programas, decisões judiciais e regulações administrativas 
deveriam ser encarados como potencialidades, com sua realização dependendo tanto de suas qualidades intrínsecas quanto das circunstâncias externas. Para estes autores, implementação é evolução.

Quão bem políticas respondem a oportunidades, quão bem elas facilitam adaptações e correções de erros, são qualidades insuficientemente discutidas. Para nossos propósitos, contudo, é mais importante observar que a condição ordinária da administração é manter as coisas acontecendo, mais do que fazer as coisas começarem. Não é o desenho de políticas, mas o redesenho que ocorre a maior parte do tempo (Majone \& Wildavsky, 1995, p. 146).

Pressman e Wildavsky (1984) escreveram uma obra considerada precursora sobre implementação, cuja primeira edição é de 1973. Quanto à questão retórica sobre o que de fato se implanta na implementação, esses autores respondem: uma política, naturalmente. Entretanto,

Conforme constatado na terceira edição de sua obra (1984), ... é perigoso considerar como evidente o fato de os implantadores estarem trabalhando com uma entidade identificável que pode ser chamada de política. A política [pública] é, de fato, um conceito escorregadio, que somente poderá emergir por meio de um elaborado processo que tende a incluir estágios convencionalmente descritos como implementação (Hill, 2006, p. 67).

O referido autor cita, entre outras dificuldades para definir uma política, a coprodução da atividade reguladora entre regulador e regulado (por uma série de razões, entre as quais o fato de que muitas vezes o regulado entende mais do processo que o regulador) e a própria complexidade de certas políticas. Hill (2006) observa que "se isso [a complexidade e confusão de tantas políticas] é verdade para uma Inglaterra unificada, centralizada, dominada por um só partido, o que dizer de sociedades em que a política é marcada por compromissos entre unidades federadas e governos coligados?” (p. 84). O autor conclui que, no estudo da implementação, é difícil ir além da identificação de elementos-chave, que devem ser analisados, e do reconhecimento da enorme importância da negociação e da barganha, que ocorrem durante o processo das políticas públicas.

Arretche (2001), discorrendo sobre a necessidade de se obter cooperação, afirma que "os agentes formuladores e implantadores experientes e com poder decisório tendem a escolher estratégias de implementação pautadas muito mais por sua potencial aceitação do que por sua esperada eficiência ou efetividade" (p. 5). É uma orientação ponderada, que tem eco na literatura. Majone e Wildavsky (1995), contudo, ressalvam que o fim de uma política não é a satisfação dos implantadores: "Nós sentimos que a ênfase no consenso, na barganha e em manobras políticas pode facilmente levar (e, de fato, tem levado) à concepção de que a implementação é a própria recompensa [dos implantadores]" (p. 143). É uma crítica que entendemos válida, para que não se confundam meios e fins.

De acordo com Farah (2011, p. 820), “nas últimas décadas, o 'público' da administração pública foi redefinido, ampliando suas fronteiras para além do Estado" - ou Estado-rede, conforme conceito de Castells (1998). Arretche (2001, p. 9) observa que "Atualmente, raros são os programas que não são implantados no contexto de um sistema de relações intergovernamentais e de parcerias as mais diversas com a sociedade civil"'. Organizações públicas estão, de fato, enredadas em teias de relações formais e informais, dentro das quais os gestores públicos orientam seus processos de deliberação e elaboração de políticas (Park \& Rethemeyer, 2014).

A propósito da avaliação, Costa e Castanhar (2003) ponderam que avaliar é examinar sistemática e objetivamente um projeto ou programa, finalizado ou em curso, com vista à determinação de sua eficiência, efetividade, impacto, sustentabilidade e relevância de seus objetivos, sendo atividade não restrita à etapa final do ciclo da política. Com base em Figueiredo e Figueiredo (1986), Arretche (1998) afirma que "a particularidade da avaliação de políticas públicas consiste na adoção de métodos e técnicas de pesquisa que permitam estabelecer uma relação de causalidade entre um programa $x$ e um resultado $y$, ou ainda que, na ausência do programa $x$, não teríamos o resultado $y$ " (Arretche, 1998, p. 3). Conforme discutido antes, tenha-se em conta que o programa $x$ implantado dificilmente coincidirá com o que foi originalmente formulado. A mesma autora, em texto posterior (Arretche, 2001), alerta para o risco de 
avaliações precipitadas (ingênuas, no dizer dela) concluírem pelo fracasso de um programa sob avaliação, caso não se considere a grande distância entre formulação e implementação.

Behn (1995) destaca a medição dos resultados de uma política - para o que são necessários dados e informações - como uma das grandes questões da administração pública. A despeito da importância, a pesquisa e a prática da avaliação no Brasil ainda têm muito que evoluir (Capobiango, Silveira, Zerbato, \& Mendes, 2011). Mesmo internacionalmente, não é incomum que a análise de políticas públicas negligencie a etapa de avaliação (Hoerner \& Stephenson, 2012).

Martes, Arretche, Melo e Ribeiro (1999) mencionam a necessidade de planejar a avaliação. Mas esse planejamento nem sempre acontece. No caso de avaliações internas não planejadas, seria comum produzir-se "um transtorno na rotina dos subordinados que, sem as condições apropriadas, vão desenvolver esforços adicionais de monta na busca de informações não organizadas, de dados defasados e pouco confiáveis, de opiniões pessoais, de evidências factuais esparsas" (Garcia, 2001, p. 7). Ainda no tocante à falta de planejamento, o autor pondera que avaliações de políticas não desenhadas para serem avaliadas tendem a ser precárias e inconclusas, principalmente se externas.

Isto porque não é possível, passado o tempo da implementação, mapear de forma precisa a situação inicial que deveria ser alterada pela política/programa/projeto, contrastando-a com a situação presente ou com a final. Também não é possível reconstruir todo o processo de intervenção, em suas múltiplas dimensões, nem os contextos particulares nos quais seus diversos segmentos ocorreram. De igual maneira, não é possível reconstituir os caminhos e as circunstâncias que levaram ao erro ou ao acerto, prescrevendo sugestões corretivas. Torna-se, portanto, extremamente difícil, senão temeroso, estabelecer relações causais entre as ações desenvolvidas e os resultados alcançados, sejam estes previstos ou não, desejados ou não, primários ou secundários, restritos ou ampliados (Garcia, 2001, p. 12).

Implicitamente, o autor propõe que haja certa coincidência temporal entre o planejamento da avaliação e a própria formulação da política. Informações oportunas "existirão apenas quando a ação [o programa, o projeto ou a política] tiver sido desenhada e programada de forma a permitir que se cumpra a exigência de produzir informações apropriadas a um ritmo adequado à tomada de decisões" (Garcia, 2001, p. 30). Uma consequência desse raciocínio, ainda segundo o autor, seria a necessidade de estabelecer a obrigatoriedade de registro das informações fundamentais ainda na etapa de formulação.

Vale notar uma ressalva deste autor, alertando para a pretensão da informação completa: seria um erro relacionar a qualidade da decisão governamental ao acesso a informações desse nível. Para Capitani (1993, como citado em Garcia, 2001, p. 17): "Esse é o tipo de erro que os economistas cometem ao adotar um mundo de informações completas, de perfeita racionalidade, amigável e sem fronteiras", mundo que não teria correspondência com a realidade governamental. "Ademais, as capacidades individuais e institucionais de processamento de informações são limitadas. Muita informação desinforma. Por outro lado, a grande maioria das decisões está voltada para a busca de soluções satisfatórias e não de soluções ótimas" (Garcia, 2001, p. 17). O autor frisa que informações oportunas, tempestivas, são mais importantes que aquelas supostamente completas. Se tal recomendação, levada a cabo, evita o desperdício de esforços, não ajuda a tornar mais fácil o processo de avaliação.

Entre os muitos fatores que fazem da avaliação um desafio teórico e prático, salientamos o entrelaçamento de processos. A literatura consultada, parcialmente retratada nesta seção, evidencia que formulação, implementação e avaliação de políticas públicas são processos fortemente imbricados.

O caráter eminentemente político da avaliação de políticas públicas (Faria, 2005) torna ainda mais complexo o entrelaçamento entre formulação, implementação e avaliação. Considerando o embate de interesses conflitantes próprios da política, definir a avaliação ex ante (ainda que apenas uma parte dela) poderia acrescentar dificuldades à formulação da política pública. Na linha dos obstáculos, cabe mencionar também a questão dos custos de obtenção de informações, em particular no âmbito do sistema financeiro (Boot \& Thakor, 1997). A informação não se distribui uniformemente e, por seu eventual valor estratégico, muitas vezes fica escondida nas instituições que a detêm (Grossman \& Stiglitz, 1980). 


\section{Metodologia}

O estudo apresentado neste artigo adota uma abordagem qualitativa, com base em um estudo de caso único. De acordo com Hammersley, Gomm e Foster (2009), uma das justificativas para o estudo de caso único é a revelação de processos causais em sistemas de baixa visibilidade externa, situação que se enquadra nesta pesquisa. A unidade de análise retratada é a política pública para inclusão financeira liderada pelo BC, a partir da qual se discute a importância e os limites da previsão antecipada de dados.

O caso abrange o período de 1999 a 2012. O corte inicial corresponde ao ano em que ocorreram ações regulamentares marcantes do BC relacionadas à inclusão financeira, descritas na próxima seção, e o final explica-se pelo momento da pesquisa, iniciada em 2012 e encerrada em julho de 2013.

Como fontes secundárias, foram usados diversos relatórios e publicações disponibilizados pelo $\mathrm{BC}$ em seu website, inclusive os diversos anais dos fóruns de inclusão financeira promovidos por esta instituição no período considerado, assim como Resoluções do Conselho Monetário Nacional (CMN) sobre o tema. Além desses dados públicos, foram analisados documentos internos do BC, como os planos dos projetos Inclusão Financeira I e II.

Os dados primários foram coletados por meio de entrevistas semiestruturadas, realizadas entre novembro de 2012 e junho de 2013, com funcionárias de carreira do BC envolvidas na formulação da política de inclusão financeira, a saber: a chefe e uma assessora plena do Departamento de Educação Financeira e a chefe da divisão Instituições Bancárias e Inclusão Financeira do Departamento de Normas do Sistema Financeiro. Ressalte-se que a chefe do Departamento de Educação Financeira foi gerente dos projetos estratégicos Inclusão Financeira I e II (2009 a 2013), e a assessora fez parte das equipes desses mesmos projetos.

\section{A Atuação do BC para a Inclusão Financeira (Período 1999-2012)}

Em seu II Relatório de Inclusão financeira, o Banco Central (BC, 2011) enuncia que "a promoção da inclusão financeira da população constitui ação estratégica para a economia brasileira e é requisito fundamental para a manutenção da estabilidade econômica e da eficiência do SFN, favorecendo a eficácia de instrumentos de política monetária" (p. 3). Entretanto, a preocupação do BC com a inclusão financeira começou mais de uma década antes do citado relatório ser lançado.

No contexto da discussão dentro do governo federal sobre estratégias de ampliação dos programas de benefícios sociais e do microcrédito no país (Diniz, 2007), o BC lança, em 1999, três marcos regulatórios da política de inclusão financeira: a Resolução $\mathrm{n}^{\circ} 2.608$, sobre cooperativismo de crédito, a Resolução $\mathrm{n}^{\circ} 2.627$, sobre microcrédito, e a Resolução $\mathrm{n}^{\circ} 2.640$, sobre correspondentes bancários. Essa normatização foi reforçada com a criação, pelo BNDES, em 2001, do Programa de Desenvolvimento Institucional (PDI) (Nichter, Goldmark, \& Fiori, 2002) para fortalecer o segmento microfinanceiro no Brasil, em cooperação técnica com o Banco Interamericano de Desenvolvimento (BID). Nesse PDI, apontava-se como estratégias precisamente o fortalecimento das cooperativas de crédito, das instituições de microfinanças e da utilização de canais alternativos de distribuição.

A partir da edição da Resolução $n^{\circ} 2.608$, que contou na sua elaboração com a contribuição de representantes do setor cooperativista, parlamentares e técnicos do $\mathrm{BC}$, promoveu-se a estruturação das cooperativas em sistemas integrados e o aumento do público-alvo. À citada Resolução, seguiram-se outras, como a 3.106, de 2003, precedida de ampla consulta ao segmento e a representantes de vários órgãos do Poder Executivo, reunidos em grupo de trabalho coordenado pelo Ministério da Fazenda. Em sua essência, a Resolução permitiu a criação de cooperativas de livre admissão de associados, demanda antiga do mercado (segmento cooperativo). 
A Resolução n 2.627 regulamentou as Sociedades de Crédito ao Microempreendedor (SCMs). Em 2008, a Resolução $n^{\circ} 3.567$ ampliou o escopo de atuação dessas instituições, convertendo-as em Sociedades de Crédito ao Microempreendedor e à Empresa de Pequeno Porte. Entre a Resolução inicial de 1999 e a de 2008, houve outras alterações regulamentares, no bojo de normas do BC não exclusivas para as SCMs, como é o caso da Resolução $\mathrm{n}^{\circ}$ 3.156, de 2003, que facultou às SCMs e a outras instituições a contratação de correspondentes no país.

Sobre os correspondentes, são pessoas jurídicas contratadas por instituições financeiras para prestar serviços de responsabilidade da instituição contratante, como movimentação de contas ou recebimento de pagamentos, contanto que a prestação desses serviços não se constitua como sua atividade principal. Historicamente, o serviço de correspondente surgiu com a Circular n. 220, de 1973. No entanto, até a Resolução $n^{\circ}$ 2.640, de 1999, os correspondentes mantinham escopo de atividades bastante restrito, situação que foi então alterada para ampliar tanto a oferta de serviços como o perfil das instituições financeiras passíveis de contratá-los. Como afirma o BC em seus relatórios sobre inclusão financeira, a expansão dos correspondentes está diretamente relacionada com a inclusão, desde 2002, de todos os municípios brasileiros ao sistema financeiro do país. O correspondente foi uma das alternativas encontradas para a implementação de programas assistenciais, como o Bolsa Escola, criado em 2001, sem o qual não haveria como atingir as regiões mais pobres do país, com escasso acesso a serviços financeiros (Stal, 2002). Em paralelo, havia o próprio interesse dos bancos em criar alternativas de expansão do mercado com custos operacionais mais baixos, se comparados aos canais físicos tradicionais (Jayo, Diniz, Zambaldi, \& Christopoulos, 2012).

Uma medida importante para fomentar as microfinanças foi a destinação obrigatória para essa finalidade de parcela dos depósitos à vista dos bancos comerciais e de outras instituições financeiras (o que não for direcionado fica retido no $\mathrm{BC}$, sem remuneração). A exigência foi criada inicialmente pela Medida Provisória 122, de 2003, com regulamentação dada pela Resolução n ${ }^{0} 3.109$, também de 2003, com alterações sucessivas nos anos seguintes. Apesar dos incentivos para o cumprimento da exigibilidade (como a possibilidade de repassar recursos a outras instituições financeiras), grande parte dos valores disponíveis, por opção das instituições captadoras, não foi direcionada às operações microfinanceiras.

Em 2003, duas outras Resoluções foram editadas no âmbito do BC para impulsionar a inclusão financeira: a 3.104 e a 3.113, que criaram as contas-correntes e de poupança simplificadas, facilitando o processo de abertura de contas isentas de tarifas. As contas simplificadas se juntam aos correspondentes como elementos de extrema importância para a execução dos pagamentos relacionados ao Programa Bolsa Família.

As resoluções mencionadas são todas normas do CMN, com base em proposições feitas pelo BC. Tais resoluções, do mesmo modo que as Circulares do próprio BC, seguem, em regra geral, o seguinte fluxo: o tema é estudado e discutido internamente por equipes técnicas especializadas do Departamento de Normas, havendo habitualmente consultas a outros departamentos envolvidos com o assunto. Pode haver também consultas ou discussões públicas, sem prejuízo do sigilo próprio da elaboração de normas - que é um antídoto contra a informação privilegiada. Versões são produzidas até se chegar à minuta aprovada pelo Diretor de Normas, a qual, acompanhada do voto, que é a justificativa da norma, é apresentada na reunião da Diretoria Colegiada do BC. Se aprovada, publica-se como Circular do BC, se o assunto for de competência dessa autarquia ou, se for de competência do CMN, remete-se a esse órgão para aprovação e publicação como Resolução do CMN.

Em abril de 2003, um documento do Ministério da Fazenda (2003) apresenta as prioridades da agenda econômica do novo governo que iniciara no início daquele ano, explicitando o desejo de ampliar o mercado de crédito, particularmente por meio de agentes microfinanceiros e cooperativas, como também dos correspondentes.

Apenas entre 2002 e 2008, em parceria com o Serviço Brasileiro de Apoio às Micro e Pequenas Empresas (Sebrae), o BC realizou nove seminários nacionais para a promover as microfinanças. Esses 
eventos, que até 2003 tinham foco exclusivamente em microcrédito, tiveram sua temática ampliada para incluir temas correlatos, como cooperativismo de crédito e moedas sociais.

A partir de 2008, cristalizou-se no BC a avaliação de que, apesar das diversas iniciativas, o desenvolvimento das microfinanças no Brasil estava aquém do esperado. Foi então que, sob impulso do Diretor de Normas e Organização do Sistema Financeiro do BC, os eventos foram reorientados para ir além da divulgação das microfinanças, acrescentando-se o objetivo de diagnosticar o setor microfinanceiro do país. Nesse contexto, criou-se um projeto estratégico que foi denominado Inclusão Financeira I - Diagnóstico e Articulação. A este projeto, que durou de 2009 e 2011, seguiu-se o projeto Inclusão Financeira II - Mapeamento e Regulação. Neste artigo, por simplificação, esses dois projetos serão considerados como fases de um mesmo projeto de inclusão financeira. Além de fazer o diagnóstico do setor microfinanceiro, pretendeu-se articular os múltiplos atores envolvidos com a inclusão financeira no país. Para tanto, contribuíram expressivamente os Fóruns Banco Central sobre Inclusão Financeira, ainda dentro da parceria com o Sebrae, realizados anualmente desde 2009. Como decorrência do primeiro Fórum, empreendeu-se a organização e consolidação de dados e informações sobre o assunto, com o objetivo de se permitir um diagnóstico mais preciso do setor microfinanceiro nacional. A publicação dos Relatórios de Inclusão Financeira (RIFs), em 2011 e 2012, tinha esse objetivo explícito. Numa

perspectiva mais ampla, o RIF dará subsídios para monitoramento e avaliação de impactos de políticas e ações relacionadas à inclusão financeira no país, constituindo-se importante instrumento para o contínuo aprimoramento dessas políticas e para a elaboração e implementação de novas iniciativas (BC, 2010, p. 8).

Com base em dados e informações organizados, essa avaliação planejada distingue-se do padrão seguido pelo BC até então. Na prática, até o advento do projeto Inclusão Financeira e dos RIFs, a avaliação era quase que exclusivamente informal e baseada em subsídios coletados junto ao mercado, seja por meio das áreas de fiscalização e atendimento ao público, seja por meio de contatos de cunho mais corporativo com associações, instituições financeiras, agentes microfinanceiros e interessados em geral no tema.

O próprio caráter de diagnóstico desse novo ciclo gerou a necessidade de coletar e organizar dados e informações internos do setor microfinanceiro. Aqui nota-se o sinal de que a política foi sendo desenhada e implantada sem previsão inicial de avaliação formal. Os eventos de inclusão financeira que o BC promoveu ou dos quais participou a partir de1999, a par de seus objetivos específicos, responderam também à necessidade de avaliar, por intermédio da interação com o mercado, os resultados das ações implantadas.

Para a elaboração dos RIFs, foram utilizados dados enviados pelas instituições supervisionadas pelo $\mathrm{BC}$, combinados com dados produzidos pelo Instituto Brasileiro de Geografia e Estatística (IBGE). A reunião e a consolidação dos dados e informações disponíveis nas bases do $\mathrm{BC}$ não foram tarefas fáceis. Membros da equipe do projeto foram designados para trabalhar exclusivamente nessa tarefa, interagindo frequentemente com funcionários dos departamentos que administram as referidas bases algumas das quais são muito grandes, como a que monitora o crédito. Para se obter os dados e informações visados, foi preciso um trabalho imenso de depuração. Entre outras dificuldades operacionais vividas pela equipe do projeto, pode-se mencionar a diferença entre os códigos de municípios utilizados em uma base do BC (de dados cadastrais das instituições reguladas) e aqueles empregados em uma base do IBGE, o que exigiu muitos ajustes manuais.

A propósito dos grandes seminários promovidos pelo $\mathrm{BC}$ em parceria com o Sebrae durante o período considerado (1999 a 2012), é interessante notar como a evolução conceitual microcréditomicrofinanças-inclusão financeira refletiu-se na temática desses eventos: os dois primeiros foram sobre microcrédito (2002 e 2003), os sete seguintes foram sobre microfinanças (2003 a 2008), e os quatro últimos, sobre inclusão financeira (2009 a 2012). 
Entre 2010 e 2011, o BC introduziu a promoção da inclusão financeira como um dos seus objetivos estratégicos e lançou a Parceria Nacional para Inclusão Financeira (PNIF). A PNIF é uma "rede de atores públicos e privados engajados em ações coordenadas para a promoção da adequada inclusão financeira da população brasileira" (BC, 2012, p.4), conforme definição encontrada no Plano de Ação para Fortalecimento do Ambiente Institucional, que é um dos produtos da referida parceria. O Plano de Ação de 2012 prevê iniciativas a serem implantadas até 2014 e aponta os responsáveis pela coordenação de cada ação. Nessas coordenações, além do BC (que participa de todas), contam-se diversos órgãos governamentais, dado que a inclusão financeira demanda competências variadas. Ilustrativamente, podem-se citar as múltiplas alçadas regulatórias, representadas pela Comissão de Valores Mobiliários (CVM), pela Superintendência Nacional de Previdência Complementar (Previc) e pela Superintendência de Seguros Privados (Susep), assim como pelo próprio BC.

\section{Análise do Caso}

Antes de responder às questões de pesquisa que nortearam este estudo, faz-se necessário entender a dinâmica da política em foco, que tem como uma de suas características ser implantada majoritariamente por atores independentes - as instituições financeiras reguladas pelo BC. Sendo assim, entendemos que a abordagem top-down não dá conta de analisar a referida política. Segundo essa abordagem, "seria possível assegurar a fidelidade da implementação ao desenho proposto inicialmente" (Silva \& Melo, 2000, p. 8) - algo virtualmente impossível com os implantadores, que têm de fato um enorme grau de liberdade ${ }^{(1)}$.

A implementação não é uma decorrência automática da formulação, especialmente em situações de grande autonomia dos implantadores. Kozhikode e Li (2012), em um estudo sobre expansão de agências bancárias na Índia, mostram como determinadas situações políticas podem reduzir o poder do governo na implantação de políticas públicas que dependem de agentes privados para serem acionadas. Contribuições surgidas dos processos típicos da fase de implementação, não previstas nos planos inicialmente formulados, demonstram que um mesmo plano pode suscitar estratégias divergentes segundo os interesses dos atores públicos e privados envolvidos (Subirats et al., 2012). Um exemplo são os correspondentes. Após as alterações regulamentares de 1999 e 2003, que ampliaram serviços e contratantes permitidos, cada instituição adotou uma estratégia para esse canal, algumas investindo muito, outras, pouco, ou ainda, outras, nada ou quase nada nesse novo formato de negócio. A maior parte dos bancos comerciais envolvidos com esse canal o utiliza ainda basicamente para recebimento de boletos - serviço que, apesar de importante na redução dos custos de deslocamento dos pagadores, de forma geral tem impacto pouco significativo para a inclusão financeira (Sanford \& Cojocaru, 2013). Esse exemplo também evidencia como o desenho da política aproxima-se mais de um marco do que de regras rígidas.

Ressalve-se, contudo, que Subirats et al. (2012) especificam os mencionados processos típicos da fase de implementação como sociopolíticos. Tal especificação retrata parcialmente o caso do BC e das instituições financeiras que implantam as políticas emanadas daquela autarquia. No texto citado, os implantadores principais são agentes públicos (autoridades suíças e espanholas), de modo que falar de processos sociopolíticos evoca diretamente o contexto desses atores. No caso da inclusão financeira liderada pelo BC, cabe explicitar os processos de mercado ou empresariais, no mínimo para dar maior clareza à expressão aplicada ao caso concreto.

De fato, grande parte das medidas adotadas pelo BC depende da adoção livre de agentes privados, conduzidos primordialmente pela lógica de mercado. Para ilustrar, tome-se o caso da destinação obrigatória para operações microfinanceiras de parcela dos depósitos à vista. O BC criou incentivos para o direcionamento dos recursos (e desestímulos ao não direcionamento), mas muitas instituições não quiseram montar a estrutura necessária ou correr os riscos envolvidos nessa atividade, ou o fizeram em proporções bastante modestas. Essas decisões afetaram fortemente a implementação da política desenhada pelo formulador. 
A implementação dos correspondentes e do direcionamento de recursos para as microfinanças é mais bem compreendida a partir da perspectiva bottom-up. Mas essa visão também não dá conta de analisar a política de inclusão financeira do BC como um todo. Majone e Wildavsky (1995), para quem implementação é evolução, propõem unir ideias (relacionadas ao plano formulado, destacado na abordagem top-down) e circunstâncias (relacionadas aos imponderáveis da implementação, enfatizados na abordagem bottom-up). Entendemos que muito dessa visão pode ser aproveitada para analisar o caso da inclusão financeira. Boa parte da atuação do BC é tipicamente evolucionária, como o evidenciam as normas que se sucedem sobre um mesmo assunto, com ajustes, aperfeiçoamentos ou inovações, fruto de uma razoável sintonia com as instituições reguladas (que são os implantadores por excelência). Em linha semelhante, Zani e Costa (2014) concluíram a necessidade de convergência entre os eixos topdown e bottom-up para analisar a implementação de determinada política pública (no caso, o financiamento da agricultura familiar por agentes bancários).

O BC busca a cooperação dos implantadores, articulando-se com eles na medida do possível, em uma forma de atuação bem distante do padrão top-down (Arretche, 2001). Mas, ao mesmo tempo, há momentos de imposição firme de regras, mesmo contra a vontade das instituições reguladas, em que fica difícil analisar a implementação da política sob uma visão radicalmente bottom-up. Ou seja, a autoridade, para impor planos e a autonomia dos implantadores, tem seu espaço no processo imbricado de formulação/implementação de uma política (Majone \& Wildavsky, 1995). Também a avaliação imbrica-se nesse processo.

A propósito, Arretche (1998) observou ser necessário, ao avaliar, levar em consideração os objetivos e a estratégia de implementação definidos pelos formuladores, pois não se pode esperar que um programa realize o que não estava em seu próprio horizonte de implementação. É o caso do direcionamento de recursos para as microfinanças (em particular, para o microcrédito): não estava entre os objetivos do BC obrigar instituições financeiras não especializadas no assunto (como bancos comerciais) a adotar essa modalidade de crédito, até em razão das características de cada instituição financeira e dos riscos envolvidos. O BC, enquanto órgão público com competências definidas, visa a uma pluralidade de objetivos, entre os quais a solidez do sistema financeiro. Promover a inclusão financeira é outro de seus objetivos, mas deve fazê-lo sem fragilizar o sistema (BC, 2011).

A citada ideia da implementação como evolução pode ser associada à avaliação de políticas públicas. A propósito, tomem-se os recorrentes ajustes regulamentares do $\mathrm{BC}$, anteriormente citados, feitos em estreito contato com o mercado (dentro dos limites da relação regulador/regulado). Esse contato muitas vezes é a principal fonte de informações para a avaliação - os eventos e grupos de trabalho associados à evolução normativa no setor cooperativo de crédito ilustram a relevância do feedback do mercado. A avaliação informal com base nesse feedback é útil, sem dúvida, mas não elimina a necessidade da avaliação planejada, com base em dados e informações organizados (Garcia, 2001; Martes, Arretche, Melo, \& Ribeiro, 1999).

Mais ainda, faz sentido prever a obtenção de parte dos dados e informações para a avaliação já na fase de formulação da política, programa ou ação. Acerca da ressalva de se prever parte dos dados e informações, as razões de fundo, bastante inter-relacionadas, são que a política continua a se fazer durante a implementação (Hill, 2006; Majone \& Wildavsky, 1995), além de existirem muitos atores fora do BC envolvidos nesse processo - outros órgãos do governo, entidades de classe, sistemas cooperativos de crédito e as próprias instituições reguladas (Farah, 2011; Martes et al., 1999; Silva \& Melo, 2000).

$\mathrm{Na}$ formulação/implementação/reformulação das políticas do BC, participam atores externos por exigência mesma do processo, que envolve questões complexas, algumas das quais são mais conhecidas pelos regulados do que pelos reguladores (Hill, 2006). O BC conta com esses atores, os quais, por sua vez, em geral querem participar (e não raro tomam a iniciativa, incitando o BC a envolvê-los). A esse respeito, pode-se citar o I Fórum Banco Central sobre Inclusão Financeira, cujos participantes externos à instituição (quase 300), a convite do $\mathrm{BC}$, ajudaram a realizar o diagnóstico do setor microfinanceiro e, indiretamente, contribuíram para a evolução normativa (Ressalve-se que, em razão do sigilo necessário, essa participação sofre restrições quanto mais se aproxima da esfera de elaboração de normas). 
A despeito das restrições, o feedback dos envolvidos/interessados nas políticas é grande e reformulador de fato. Por essa e por outras razões, anteriormente discutidas, a política formulada não é igual à implantada. Sendo assim, não faz sentido montar uma avaliação completa no momento da formulação, detalhando e prevendo todos os dados e informações necessários. Seria um desperdício prever tudo, mas um erro não prever nada. É fundamental prever ao menos aqueles dados e informações mais importantes - porque são necessários para avaliar aspectos cruciais da política - cuja coleta ou organização é mais demorada ou trabalhosa, de forma a aumentar a chance de se dispor deles tempestivamente (Behn, 1995; Garcia, 2001).

Um exemplo é a impossibilidade de se identificar o uso de serviços financeiros pelo canal de acesso. Não há nos RIFs nenhuma informação que cruze dados de uso com dados de acesso. Não é possível saber, por exemplo, qual o volume de crédito concedido ou de poupança captada pelos correspondentes. Se, como foi dito anteriormente, o próprio canal dos correspondentes foi aperfeiçoado no bojo de uma política de inclusão financeira exatamente para expandir a oferta desses serviços, é quase um contrassenso que não se consiga saber qual a efetividade deste canal como instrumento de inclusão.

A propósito, Diniz, Jayo e Christopoulos (2009), assim como Riolino e Dias (2009), reclamam da falta de dados quantitativos sobre o uso dos correspondentes, o que dificulta fazer uma avaliação precisa de seu impacto na inclusão financeira. A explicação para a não existência nos RIFs da citada informação está no fato de o BC não exigir que as instituições financeiras os enviem. A informação é fornecida ao BC apenas de forma agregada, sem distinção sobre o canal utilizado para a oferta desses serviços. Segundo os entrevistados, devido à enorme quantidade de dados e informações disponíveis no BC (ainda que em geral esparsos e não compilados), tomou-se a decisão de não fazer novas solicitações às instituições supervisionadas, sem antes explorar essa base interna.

Se a dificuldade de ir além das próprias bases de dados é compreensível, o fato é que uma informação necessária para avaliar um aspecto importante da inclusão financeira não estava disponível. Sendo importante e de obtenção não trivial, a falta de informação sobre o volume de crédito distribuído pelos correspondentes representa um exemplo de informação cuja previsão poderia ter sido feita já na fase de formulação da política, do programa ou da ação.

A obtenção da referida informação detalhada por canal esbarra em uma série de dificuldades: custos extras (para o BC e para o SFN), trabalho extra para departamentos do BC não subordinados aos gestores da política de inclusão financeira e, inclusive, questões de estratégias comerciais sigilosas das entidades supervisionadas (que poderiam ser reveladas com a exposição de certas informações). São obstáculos reais que, em vez de diminuir, aumentam a importância de se prever a obtenção dos dados e informações tidos como necessários para realizar a avaliação da política em foco. Ao optar pela previsão da necessidade desses dados na formulação da política, ganha-se tempo para negociar, obter apoios e fazer eventuais preparativos ou ajustes que ajudem a viabilizar sua obtenção.

Outros exemplos: na elaboração dos RIFs, foi difícil reunir e organizar dados a partir de bases muito grandes e não estruturadas para alguns tipos de informação que se desejava. Também demandou bastante trabalho uma diferença de códigos de municípios entre bases de dados do BC e do IBGE. Com mais tempo, talvez fosse possível criar soluções menos trabalhosas, como homogeneizar os códigos do BC e do IBGE (o que poderia ser útil para outras situações), organizar alguns dados de forma diferente ou incorporar ferramentas que fizessem a depuração de dados e a adaptação dos códigos de forma mais eficiente. São apenas hipóteses, que poderiam se viabilizar ou não. Em qualquer caso, com a previsão, que antecipa o conhecimento dos problemas, as dificuldades podem ser mais bem resolvidas.

Como ideal, convém desenhar e programar uma ação pública já com a previsão de produzir as informações necessárias para avaliações tempestivas (baseado em Garcia, 2001, p. 30). Outra justificativa para a previsão é evitar situações de emergência, que transtornam a rotina do pessoal encarregado de buscar e organizar dados e informações demandados de repente (Garcia, 2001), como de certo modo aconteceu por ocasião da elaboração dos RIFs, principalmente o primeiro. Quando dados e informações importantes não são previstos com suficiente antecedência, mais problemático que o efeito nas rotinas é o impacto negativo na tempestividade ou na qualidade das avaliações. 
A propósito da tempestividade, Garcia (2001) frisa que a informação oportuna é mais importante que aquela supostamente completa - completude, em qualquer caso, geralmente inalcançável (Simon, 1957). Trata-se, portanto, de buscar informação suficiente. Suficiência que decorre não apenas da quantidade, mas também da qualidade, porque informação de má qualidade, do mesmo modo que informação em excesso, desinforma. Definir o grau de suficiência da informação foge do escopo deste artigo, mas faz parte das decisões que os administradores públicos, nas diversas esferas de competência, precisam tomar habitualmente. Em qualquer caso, mesmo sendo um critério vago, a suficiência não deixa de fornecer alguma orientação para decidir que dados e informações devem ser previstos, quando devem ser buscados e quando essa busca/depuração pode ser encerrada.

\section{Conclusões}

Para melhor responder às questões de pesquisa formuladas na introdução do artigo, foi necessário evidenciar a dinâmica da política em foco, que tem como uma de suas características ser implantada majoritariamente por atores privados, com alto grau de autonomia. As abordagens que tratam da formulação e implementação de políticas públicas conhecidas como top-down e bottom-up não dão conta, isoladamente, de analisar a política de inclusão financeira do BC como um todo. Em decorrência da busca por articulação com os implementadores (fundamentalmente, as instituições reguladas), a atuação do BC normalmente se aproxima dos modelos bottom-up. Ao mesmo tempo, há momentos de imposição firme de regras, de exercício claro da autoridade legal, mais aos moldes da abordagem topdown. A teoria de Majone e Wildavsky (1995), que procura conciliar formulação (planos/autoridade) e implementação (autonomia), sublinhando o caráter evolutivo da implementação, mostrou-se mais adequada para analisar a política de inclusão financeira promovida pelo BC. $\mathrm{O}$ entrelaçamento entre formulação e implementação, pouco investigado do ponto de vista teórico, foi útil para analisar o caso estudado.

Quanto às questões propriamente de pesquisa, concluiu-se que é importante prever, na fase de formulação da política pública, a obtenção de parte dos dados e informações considerados necessários para avaliá-la. Quais dados e informações? Aqueles que se referem a aspectos cruciais da política e cuja coleta (ou organização) seja mais demorada ou trabalhosa, de forma a aumentar a chance de dispor deles tempestivamente. A avaliação informal com base no feedback do mercado é útil, sem dúvida, mas não elimina a necessidade da avaliação planejada, com base em dados e informações organizados. Ao mesmo tempo, seria contraproducente detalhar e prever todos os dados e informações para avaliação no momento da formulação da política (ou nas situações de redefinições pelo formulador), considerando que a política vai se definindo/reformulando também durante a implementação.

Para saber que dados e informações são considerados necessários (ou cruciais) para a avaliação da política, convém planejar a própria avaliação. Esse planejamento da avaliação, ainda que seja um pressuposto, não fez parte do escopo deste artigo, razão pela qual foi tratado apenas circunstancialmente.

Paralelamente ao problema genérico de pesquisa tratado aqui, este artigo pretendeu também contribuir para a discussão da política de inclusão financeira conduzida pelo BC. O fato deste estudo restringir-se aos dados coletados exclusivamente no $\mathrm{BC}$ e o corte temporal adotado devem ser considerados como limitações da pesquisa. Esta decisão de limitar o escopo da coleta de dados se impôs por questões da operacionalização da pesquisa, mas é preciso ter em conta que o tema da inclusão financeira tem suas origens em período anterior a 1999 e envolve não apenas o BC.

Em novas pesquisas, outros formuladores de políticas de inclusão financeira poderiam ser contemplados. Em outra direção, poderiam ser incluídos entre as fontes de dados os implementadores, que não foram ouvidos diretamente. Ampliar as fontes seria, além disso, uma forma de diminuir o viés associado à subjetividade própria da entrevista semiestruturada, que foi o método de coleta de dados primários utilizado. Quanto à estratégia de pesquisa adotada, com base em um estudo de caso único, resulta na impossibilidade de generalização estatística. Por fim, cabe observar que, por fugir do escopo 
da pesquisa, não se relacionaram características marcantes do BC, como seu perfil técnico e profissional, à maior facilidade ou dificuldade para integrar os processos de formulação, implementação e avaliação da política pública analisada.

\title{
Nota
}

\begin{abstract}
${ }^{1}$ É importante destacar que, neste artigo, os enfoques top-down e bottom-up são descritos a partir da perspectiva do setor público (no caso, o BC) como formulador de política, com o modelo bottom-up associado à autonomia (elevada) dos implementadores. Existem outras perspectivas que analisam de forma distinta esses mesmos enfoques, por exemplo, associando o modelo bottom-up à primazia da sociedade civil, inclusive como definidora de políticas (Sabatier, P. A. (1986). Top-down and bottom-up approaches to implementation research: a critical analysis and suggested synthesis. Journal of Public Policy, 6(1), 21-48. doi: 10.1017/S0143814X00003846).
\end{abstract}

\section{Referências}

Arretche, M. (1998). Tendências nos estudos sobre avaliação. In E. M. Rico (Org.), Avaliação de políticas sociais: uma questão em debate (pp. 29-49). São Paulo: Cortez.

Arretche, M. (2001). Uma contribuição para fazermos avaliações menos ingênuas. In M. C. R. N. Barreira \& M. C. B. Carvalho (Orgs.), Tendências e perspectivas na avaliação de políticas e programas sociais (pp. 43-56). São Paulo: IEE/PUC-SP.

Banco Central do Brasil. (2010). Relatório de inclusão financeira (Relatório Técnico No 1), Brasília, DF. Recuperado de www.bcb.gov.br/Nor/relincfin/relatorio_inclusao_financeira.pdf

Banco Central do Brasil. (2011). Relatório de inclusão financeira (Relatório Técnico № 2), Brasília, DF. Recuperado de www.bcb.gov.br/Nor/relincfin/RIF2011.pdf

Banco Central do Brasil. (2012). Parceria nacional para inclusão financeira: plano de ação para fortalecimento do ambiente institucional (Relatório Técnico), Brasília, DF. Recuperado de https://www.bcb.gov.br/nor/relincfin/Plano_de_Acao_PNIF.pdf

Behn, R. D. (1995). The big questions of public management. Public Administration Review, 55(4), 313-324. doi: 10.2307/977122

Boot, A. W. A., \& Thakor, A. V. (1997). Financial system architecture. The Review of Financial Studies, 10(3), 693-733. doi: 10.1093/rfs/10.3.693

Capobiango, R. P., Silveira, S. F. R., Zerbato, C., \& Mendes, A. C. A. (2011). Análise das redes de cooperação científica através do estudo das coautorias dos artigos publicados em eventos da Anpad sobre avaliação de políticas públicas. Revista de Administração Pública, 45(6), 18691890. doi 10.1590/S0034-76122011000600012

Castells, M. (1998, Marzo). Hacia el estado red? Globalizacion economica e instituciones politicas em la era de la información. Anais del Seminário Internacional Sociedad y Reforma del Estado, São Paulo, SP, Brasil. Recuperado de agendaegobierno.morelos.gob.mx/CGGD/index_htm_files/Estado\%20Red.pdf

Ceneviva, R., \& Farah, M. F. S. (2012). Avaliação, informação e responsabilização no setor público. Revista de Administração Pública, 46(4), 993-1016. doi: 10.1590/S0034-76122012000400005 
Circular n. 220, de 15 de outubro de 1973. (1973). Aos estabelecimentos bancários. Brasília, DF: Banco Central do Brasil. Recuperado de http://www.bcb.gov.br/pre/normativos/circ/1973/pdf/circ_0220_v1_O.pdf

Costa, F. L., \& Castanhar, J. C. (2003). Avaliação de programas públicos: desafios conceituais e metodológicos. Revista de Administração Pública, 37(5), 969-992.

Diniz, E. H. (2007). Correspondentes bancários e microcrédito no Brasil: tecnologia bancária e ampliação dos serviços financeiros para a população de baixa renda (Relatório de Pesquisa/2007), São Paulo, SP, GVpesquisa, Escola de Administração de Empresas, Fundação Getúlio Vargas.

Diniz, E. H., Jayo M., \& Christopoulos, T. P. (2009, September). Monitoring and evaluating microfinance delivery through ICT based correspondent banking. Proceedings of the European Conference on Information Management and Evaluation, University of Gothenburg, Gothenburg, Sweden, 3.

Dye, T. R. (1992). Understanding public policy. Englewood Cliffs, NJ: Prentice Hall.

Farah, M. F. S. (2011). Administração pública e política pública. Revista de Administração Pública, 45(3), 813-836. doi: 10.1590/S0034-76122011000300011

Faria, C. A. P. (2005). A política da avaliação de políticas públicas. Revista Brasileira de Ciências Sociais, 20(59), 97-109. doi: 10.1590/\$0102-69092005000300007

Figueiredo, M. F., \& Figueiredo, A. M. C. (1986). Avaliação política e avaliação de políticas: um quadro de referência teórica. Análise e Conjuntura, 1(3), 107-127.

Frey, K. (2000). Políticas públicas: um debate conceitual e reflexões referentes à prática da análise de políticas públicas no Brasil. Planejamento e Políticas Públicas, 21, 212-259.

Garcia, R. C. (2001). Subsídios para organizar avaliações da ação governamental (Texto para discussão, $\mathrm{N}^{\mathrm{o}}$ 776). Brasília, DF: IPEA.

Grossman, S., \& Stiglitz, J. (1980). On the impossibility of informationally efficient markets. American Economic Review, 70(3), 393-408.

Hammersley, M., Gomm, R., \& Foster, P. (2009).Case study and theory. In R. Gomm, M. Hammersley, $\&$ P. Foster (Eds.), Case study method (pp. 234-258). London: Sage.

Hill, M. (2006). Implementação: uma visão geral. In E. Saravia \& E. Ferrarezi (Eds.), Políticas públicas: coletânea (Vol. 2, pp. 61-89). Brasília: ENAP.

Hoerner, J., \& Stephenson, P. (2012). Theoretical perspectives on approaches to policy evaluation in the EU: the case of cohesion policy. Public Administration, 90(3), 699-715. doi: 10.1111/j.14679299.2011.02013.x

Jayo, M., Diniz, E. H., Zambaldi, F., \& Christopoulos, T. P. (2012). Groups of services delivered by Brazilian branchless banking and respective network integration models. Electronic Commerce Research and Applications, 11(5), 504-517. doi: 10.1016/j.elerap.2011.07.005

Kozhikode, R. K., \& Li, J. (2012). Political pluralism, public policies and organizational choices: banking branch expansion in India, 1948-2003. Academy of Management Journal, 55(2), 339359. doi: 10.5465/amj.2010.0370

Lindblom, C. (1959). The science of "muddling through". Public Administration Review, 19(2), 79-88. 
Majone, G., \& Wildavsky, A. (1995). Implementation as evolution. In S. Z. Theodoulou \& M. A. Cahn (Eds.), Public policy: the essential readings (pp. 140-152). New Jersey: Prentice Hall.

Martes, A. C. B., Arretche, M., Melo, M., \& Ribeiro, P. M. (1999). Modelo de avaliação de programas sociais prioritários (Relatório de Pesquisa), Campinas, SP, Programa de Apoio à Gestão Social no Brasil Campinas, Núcleo de Estudos em Políticas Públicas, Universidade Estadual de Campinas.

Medida Provisória n. 122, de 25 de junho 2003. (2003). Dispõe sobre o direcionamento de depósitos à vista captados pelas instituições financeiras para operações de crédito destinadas à população de baixa renda e a microempreendedores, autoriza o Poder Executivo a instituir o Programa de Incentivo à Implementação de Projetos de Interesse Social - PIPS, e dá outras providências. Brasília, DF. Recuperado de http://www.planalto.gov.br/ccivil_03/mpv/Antigas_2003/122.htm

Melo, M. A. (1999). Estado, governo e políticas públicas. In S. Miceli (Org.), O que ler na ciência social brasileira (1970-1995) (pp. 59-100). São Paulo: Sumaré.

Ministério da Fazenda. (2003). Política econômica e reformas estruturais. Brasília, DF. Recuperado de http://www.fedepsp.org.br/superior/politica_econ_ref_estrut.pdf

Nichter, S., Goldmark, L., \& Fiori, A. (2002). Entendendo as microfinanças no contexto brasileiro (Relatório de Pesquisa), Rio de Janeiro, RJ, Banco Nacional de Desenvolvimento Econômico e Social.

Park, H. H., \& Rethemeyer, R. K. (2014).The politics of connections: assessing the determinants of social structure in policy networks. The Journal of Public Administration Research and Theory, 24(2), 349-379. doi: 10.1093/jopart/mus021

Pressman, J. L., \& Wildavsky, A. B. (1984). Implementation (3a ed.). Berkeley: University of California Press.

Ramos, M. P., \& Schabbach, L. M. (2012). O estado da arte da avaliação de políticas públicas: conceituação e exemplos de avaliação no Brasil. Revista de Administração Pública, 46(5), 12711294. doi: $10.1590 / \mathrm{S} 0034-76122012000500005$

Resolução n. 2.608, de 27 de maio de 1999. (1999). Aprova o regulamento que disciplina a constituição e o funcionamento de cooperativas de crédito. Brasília, DF: Conselho Monetário Nacional. Recuperado de http://www.bcb.gov.br/pre/normativos/res/1999/pdf/res_2608_v1_O.pdf

Resolução n. 2.627, de 2 de agosto de 1999. (1999). Dispõe sobre a constituição e o funcionamento de sociedades de crédito ao microempreendedor. Brasília, DF: Conselho Monetário Nacional. Recuperado de http://www.bcb.gov.br/pre/normativos/res/1999/pdf/res_2627_v1_O.pdf

Resolução n. 2.640, de 25 de agosto de 1999. (1999). Dispõe sobre a contratação de correspondentes no País. Brasília, DF: Conselho Monetário Nacional. Recuperado de http://www.bcb.gov.br/pre/normativos/res/1999/pdf/res_2640_v1_O.pdf

Resolução n. 3.104, de 25 de junho de 2003. (2003). Dispõe sobre a abertura de contas especiais de depósitos à vista. Brasília, DF: Conselho Monetário Nacional. Recuperado, de http://www.bcb.gov.br/pre/normativos/res/2003/pdf/res_3104_v1_O.pdf

Resolução n. 3.109, de 24 de julho de 2003. (2003). Dispõe acerca da realização de operações de microfinanças destinadas à população de baixa renda e a microempreendedores. Brasília, DF: Conselho Monetário Nacional. Recuperado de http://www.bcb.gov.br/pre/normativos/res/2003/pdf/res_3109_v1_O.pdf

Resolução n. 3.113, de 31 de julho de 2003. (2003). Altera o art. $4^{\circ}$ da resolução 3.104, de 2003, que dispõe sobre a abertura de contas especiais de depósitos à vista, e estabelece normas relativamente 
à abertura de contas de depósitos de poupança. Brasília, DF: Conselho Monetário Nacional. Recuperado de http://www.bcb.gov.br/pre/normativos/res/2003/pdf/res_3113_v1_O.pdf

Resolução n. 3.156, de 17 de dezembro de 2003. (2003). Altera a resolução 3.110, de 2003, que dispõe sobre a contratação de correspondentes no País. Brasília, DF: Conselho Monetário Nacional. Recuperado de http://www.bcb.gov.br/pre/normativos/res/2003/pdf/res_3156_v1_O.pdf

Resolução n. 3.567, de 29 de maio de 2008. (2008). Dispõe sobre a constituição e o funcionamento de sociedades de crédito ao microempreendedor e à empresa de pequeno porte. Brasília, DF: Conselho Monetário Nacional. Recuperado de http://www.bcb.gov.br/pre/normativos/res/2008/pdf/res_3567_v1_O.pdf

Riolino, R. P. F., \& Dias, D. (2009). Branchless banking and consumer protection in Brazil (Research Report), Washington, DC, Consultative Group to Assist the Poor.

Sanford, C., \& Cojocaru, L. (2013). Do correspondents improve financial inclusion? Evidence from a national survey in Brazil (Research Report), Somerville, MA, Bankable Frontier Associates.

Secchi, L. (2010). Políticas públicas: conceitos, esquemas de análise, casos práticos. São Paulo: Cengage Learning.

Silva, P. L. B., \& Melo, M. A. B. (2000). O processo de implementação de políticas públicas no Brasil: características e determinantes de avaliação de programas e projetos [Cadernos de Pesquisa, $\mathrm{N}^{\circ}$ 48], Campinas: Núcleo de Estudos de Políticas Públicas/Unicamp.

Simon, H. (1957). Comportamento administrativo. Rio de Janeiro: USAID.

Souza, C. (2006). Políticas públicas: uma revisão da literatura. Sociologias, 16, 20-45. doi: $10.1590 /$ S $1517-45222006000200003$

Stal, I. L. (2002, Octubre). Bolsa escola como alternativa de inclusão social. Congreso Internacional del CLAD sobre la Reforma del Estado y de la Administración Pública. Lisboa, Portugal, 7.

Subirats, J., Knowepfel, P., Larrue, C., \& Varone, F. (2012). Análisis y gestión de políticas públicas (2a ed.). Barcelona: Editorial Planeta.

Zani, F. B., \& Costa, F. L. (2014). Avaliação da implementação do programa nacional de fortalecimento da agricultura familiar - novas perspectivas de análise. Revista de Administração Pública, 48(4), 889-912. doi: 10.1590/0034-76121555

\title{
Dados dos Autores
}

\author{
Marcelo Machado Teixeira de Andrade \\ Av. Paulista, 1804, Cerqueira César, 01310-922, São Paulo, SP, Brasil. E-mail: marcelo.andrade@bcb.gov.br \\ Eduardo Henrique Diniz \\ Rua Itapeva, 474, 01313-902, São Paulo, SP, Brasil. E-mail: eduardo.diniz@fgv.br
}

